\title{
Reflexões sobre a História do Pensamento Econômico Brasileiro
}

\section{Some Reflections on History of Brazilian Economic Though}

Angela Ganem*

Resumo: Este artigo tem como objetivo refletir sobre a História do Pensamento Econômico Brasileiro (HPEB), explorando particularidades da trajetória de uma economia retardatária, atrasada, subdesenvolvida, periférica, dependente e engajada no capitalismo constituído das economias centrais. Partimos da ideia de que, para reconstruir a história da produção teórica de um país, de uma região ou de uma civilização, faz-se necessário praticar um duplo movimento: com a história econômicosocial e com a história das ideias. Nesse sentido, o trabalho identifica, ainda que de forma embrionária, influências de matrizes do pensamento das economias centrais nas teorias elaboradas por nossos pensadores, através de releituras conceituais, adaptações teóricas e criação de novos conceitos. O trabalho constata ainda especificidades do objeto HPEB, como o seu caráter plural e interdisciplinar, além de uma trajetória intrinsecamente ligada à política e às instituições, tal como ocorre com a história do capitalismo brasileiro.

Palavras-chave: Pensamento Econômico Brasileiro. Influências das matrizes teóricas. Especificidades.

Abstract: This essay aims to reflect on the History of Brazilian Economic Thought (HPEB), exploring the trajectory of a particular economy laggard, backward, underdeveloped, peripheral, dependent and engaged in a capitalism of the central economies. We start with the idea that to reconstruct the history of theoretical production of a country, a region or a civilization it is necessary to practice a double movement: the economic, social history and the history of ideas. In this sense, the work identifies, albeit in embryonic form, influences of matrices of thought of central economies in the theories developed by our thinkers, through conceptual readings, adaptations and creation of new theoretical concepts. The study also notes HPEB specific object, as its plural and interdisciplinary, in addition to a trend intrinsically linked to politics and political institutions, such as with the history of brazilian capitalism.

Keywords: Brazilian Economic Thought. Influence of matrices's thought. Specifics objects.

JEL Classification: B40.

Professora visitante do Instituto de Economia da Universidade Federal do Rio de Janeiro (UFRJ). Email: aganem@terra.com.br 


\section{Introdução}

Este artigo tem como objetivo refletir sobre a História do Pensamento Econômico Brasileiro (HPEB), explorando particularidades da trajetória de uma economia retardatária, atrasada, subdesenvolvida, periférica, dependente e engajada no capitalismo constituído das economias centrais. Partimos da ideia de que, para reconstruir a história da produção teórica de um país, de uma região ou de uma civilização, faz-se necessário praticar um duplo movimento: com a história econômico-social e com a história das ideias. Nesse sentido, um dos objetivos do trabalho é identificar, ainda que de forma embrionária, influências das matrizes do pensamento das economias centrais nas teorias elaboradas por nossos pensadores. Esse esforço nos permite apontar releituras conceituais, adaptações teóricas e a criação de novos conceitos que pretendem dar conta da especificidade do objeto.

Ainda nesse campo conceitual e interpretativo, a influência teórica das várias matrizes do centro sobre nossos pensadores dota a HPEB de um caráter plural e interdisciplinar. No Brasil, as características de pluralidade e de interdisciplinaridade podem ser observadas tanto no plano autoral como na multiplicidade de perspectivas teóricas voltadas para a análise do capitalismo brasileiro. A inserção do Brasil no quadro do desenvolvimento do capitalismo e nas formas políticas praticadas para superar a pobreza explica a íntima ligação do pensamento brasileiro com a temática do desenvolvimento e da superação do subdesenvolvimento, questão que tem organizado a leitura da HPEB.

Além disso, é possível constatar que o pensamento econômico no Brasil se faz e se consolida ligado à política e às instituições, tal como ocorre com a história do capitalismo brasileiro. O trabalho aborda esses temas, valendo-se das contribuições dos autores, dos sistematizadores da HPEB e, sobretudo, da perspectiva de Malta et al. (2009), que entende a história do pensamento como um espaço privilegiado das controvérsias e que busca integrar a economia à história, à política e à ideologia. ${ }^{1}$

\section{A HPEB e sua relação com a História do Capitalismo e com a História das Ideias}

Uma perspectiva crítica da História do Pensamento Econômico envolve o exercício de um duplo movimento: com a história econômico-social e com a história das ideias. O pensamento econômico sistematizado nasce com o

1 A HPEB desse período (1964/1988) foi sistematizada por Bielschowsky e Mussi (2005), Mantega (1997) e Bresser-Pereira (1997). O trabalho de maior fôlego é o de Ricardo Bielschowsky e Carlos Mussi, que organiza a HPEB por ciclos ideológicos (dentro da linha do clássico de Bielschowsky, Pensamento Econômico Brasileiro: o Ciclo Ideológico do Desenvolvimento, publicado em 1988). Já Guido Mantega a sistematiza por correntes, e Bresser Pereira, por pactos e interpretações. A proposta metodológica de Malta et al. (2009) vem se somar às demais leituras sistematizadoras da HPEB, mas num outro plano de desafio: o de explorar as principais controvérsias do período articulando a teoria à história, à política e à ideologia. 
surgimento do capitalismo e com a história das ideias da modernidade, esta última responsável pelo processo de construção do ideário liberal. A história econômico-social fornece a referência maior na qual se circunscrevem as ideias. Entretanto, elas são um jogo vivo de saberes, um manancial fértil para novas hipóteses propositoras, enfim, um campo inesgotável de investigação.

Reconstruir a História do Pensamento Econômico dentro de uma perspectiva crítica significa compreendê-la como um registro mediado por fatos econômico-sociais e articulado as ideias. Isso significa que não existe uma autonomização das ideias em que se celebra o gênio desgarrado de sua inserção histórica. Sobre o segundo aspecto, Tolipan (1982, p. 2) afirma: “[...] ela [a HPE] não pode ser entendida como algo enciclopédico, uma câmara mortuária dos conteúdos do passado, ou um catálogo de mônadas teóricas sem vínculo orgânico com o conjunto de ideias que conformara a questão".

Uma HPE crítica refuta a ideia da história do progresso científico como um processo acumulativo linear que nos leva inexoravelmente a uma verdade absoluta em que o atual estágio do desenvolvimento teórico da ciência econômica estaria atestado pelos últimos avanços modelísticos e matemáticos do mainstream. Essa perspectiva positivista tem a pretensão de fazer tábula rasa da história, tornando-a desnecessária, supérflua, ou ainda apenas objeto de curiosidade intelectual, a inserção das contribuições teóricas no tempo. $\mathrm{O}$ que importa nesse caso é o atual estágio analítico, fiel depositário acumulado dos resultados analíticos recentes. Uma HPEB crítica, além de estabelecer um movimento das ideias com os fatos históricos, deve ser entendida como um combate de ideias, eminentemente plural e conflitivo, o espaço da controvérsia, o espaço da liberdade.

A HPE das economias centrais, nesses últimos três séculos, testemunha a dinâmica da economia como ciência, acumulando um amplo espectro de teorias e métodos e caracterizando-se por uma natureza plural e aberta às controvérsias. Traçando em grandes linhas o processo histórico dessa ciência, podemos identificar movimentos teóricos catalisadores que nos ajudam a perceber os diferentes caminhos trilhados por seus teóricos, alguns em clara oposição no que diz respeito à compreensão da natureza da economia e aos métodos mais apropriados para tratá-la.

A economia política nasce com a implantação do capitalismo e como fruto da modernidade. No século XVIII, é possível construir um consenso em torno de Adam Smith como seu marco fundador. Ele a inaugura com uma interpretação sistematizada da ordem social capitalista, observando-a tanto pela ótica da produção, da acumulação e do excedente, como pela forma mercado. ${ }^{2}$

2 Ainda há uma terceira leitura sobre Adam Smith e o nascimento da economia, caracteristicamente interdisciplinar. Nela, é inconcebível a ideia da economia como ciência, livre da moral e do príncipe. Faz parte dessa perspectiva o esforço de inúmeros pesquisadores de unir as duas obras do autor: a Teoria dos Sentimentos Morais e a Riqueza das Nações. Essa questão da possibilidade de união ou não do filósofo com o economista gerou uma importante controvérsia sobre a natureza da economia, conhecida como o "problema Adam Smith", ou Adam Smith Problem. Ver, a propósito, Bertrand (1994), Bianchi (1988), Dupuy (1992), Ganem (2000, 2002), Raphael e Macfie (1976). 
A ótica da produção, da acumulação e do excedente econômico analisada no quadro histórico-social está ligada ao caminho aberto no século XVII por William Petty e desenvolvido por Adam Smith e pelos fisiocratas no século XVIII. Já a leitura pela ótica do mercado remete Smith à história das ideias, em especial sua participação na construção do ideário liberal, um processo que é inaugurado na revolução científica moderna e desenvolvido na filosofia política e moral dos séculos XVII e XVIII. A solução da mão invisível, em que interesses privados, em vez de se chocarem, produzem bem-estar social, contrapõe e supera as formulações do contrato para a explicação da ordem social liberal nascente e é considerada por inúmeros autores como a palavra final da modernidade.

Os neoclássicos em fins do século XIX, no intento de fornecer respostas metodológicas (leia-se provas matemáticas) a uma ciência pautada pelo espelho da física, estreitam o raio de ação da economia e procedem a um reducionismo no tratamento dos fenômenos econômicos, traduzindo Smith aos seus próprios termos. Afastam-se teoricamente da questão do desenvolvimento e concentram-se exclusivamente nas questões alocativas do mercado. Os neoclássicos da primeira leva (revolução marginalista) releem a ideia da mão invisível smithiana e a compreendem como uma ordem racional passível de ser demonstrada matematicamente (GANEM, 1996).

Nesse momento histórico, duas perspectivas teóricas opostas acerca da natureza da economia e da origem do valor coexistem. Um mesmo objeto - o capitalismo - tratado de formas diferentes, ou uma mesma ciência, com dois enfoques distintos: a economics e a economia política crítica de Marx.

Eclipsado dentro da academia e articulando claramente a economia com a política, a história e a sociedade, Marx retoma o tema central de Smith e Ricardo ao desenvolver a teoria do valor-trabalho e explicar a origem do excedente na estrutura produtiva. Nesse intento, a história é o elemento esclarecedor do papel dos conflitos entre as classes sociais na análise da dinâmica das contradições e das possibilidades de superação do capitalismo como modo de produção e ordem social. Essas duas vertentes do pensamento situam-se claramente em campos opostos na política e como projetos de sociedade, cujos delineamentos ficarão mais claros no século XX: o projeto socialista de um lado, com seus desdobramentos teóricos e políticos, e o mercado como ordem espontânea e fim da história em Hayek. ${ }^{3}$

O século XX traz a novidade do aprofundamento da pluralidade teórica no pensamento econômico embora o programa neoclássico de pesquisa impere inconteste, pelo menos, até a crise de 1929. São várias as correntes de pensamento que surgem na figura de autores como Keynes, Schumpeter, Sraffa e Kalecki, que se desdobram por sua vez numa multiplicidade de escolas de pensamento, como os sraffianos, os pós-keynesianos, os institucionalistas,

Em fins do século XX, no campo doutrinário, discursos apologéticos elegeram entusiasticamente o mercado, como passado, presente e devir das sociedades contemporâneas. Uma nova teoria do mercado, menos matemática e mais afinada a seu tempo, foi um dos grandes pilares desse discurso: a teoria do mercado espontâneo de F. A. Hayek. 
os neoschumpeterianos, os neomarxistas, os regulacionistas franceses, os evolucionários e os estruturalistas cepalinos, para citar os mais representativos. A identificação da estrutura desses últimos programas de pesquisa, suas evoluções, bem como suas degenerescências (no sentido lakatosiano) é um dos objetos de estudo da epistemologia contemporânea. ${ }^{4}$

A presença dessas inúmeras escolas confirma o fosso existente entre a perspectiva "cristalina" do programa neoclássico de pesquisa e as perspectivas metodológicas críticas alternativas, ou o campo da heterodoxia, como muitos preferem denominar. A primeira perspectiva com seus fundamentos restritivos e rigorosos de pesquisa, assentados na otimização e no equilíbrio como noções centrais, tem a ideia forte de que a modelização ou a complexidade crescente de cálculos é critério de cientificidade necessário e suficiente à entrada da ciência econômica no reino das hard sciences. Some-se a esses elementos a perspectiva dogmática do programa, que, por seus critérios definidores de cientificidade, se autoconsidera o representante dos avanços da ciência econômica, e os demais, vistos por ele, como retórica ou literatura. Já a segunda perspectiva se expressa na pluralidade de discursos e nas possibilidades inesgotáveis de diálogo e aproximações entre as escolas. Essa perspectiva crítica tem a enfrentar uma multiplicidade de desafios, que vão desde a complexidade cognitiva do sujeito e da ação humana, a concepção do tempo como aberto e irreversível, as trajetórias entendidas como não determinísticas, a consideração das instituições, a importância dos valores e da ética, a interdisciplinaridade e a necessidade da história, leito sobre o qual as teorias e os métodos se desenvolvem (GANEM, 2003).

Será no esteio desse quadro plural de reflexões dos vários programas de pesquisa que as primeiras formulações teóricas sobre o capitalismo brasileiro surgem e se desenvolvem. Pensar a HPEB é, portanto, partir dessas reflexões acumuladas no centro para tecer, num processo conjunto, as particularidades e identificações que nossa história econômica/social/cultural dependente e associada exigiu.

A busca pela compreensão das economias retardatárias, atrasadas, subdesenvolvidas se fez no Brasil na segunda metade do século XX. A HPEB e a história do pensamento latino-americano surgem no quadro de teorias maduras sobre o capitalismo constituído nas economias centrais. Em outras palavras, a reflexão sistematizada da Comissão Econômica para a América Latina e o Caribe (Cepal) ocorre séculos após a inserção desses países como economias coloniais no quadro da modernidade e no processo de acumulação de capital das economias centrais.

4 A estrutura dos Programas de Pesquisa de Lakatos é composta por um núcleo duro e um cinturão protetor. O hard core é constituído de teorias infalsificáveis por decisão de seus protagonistas. Para a física pura, por exemplo, são as leis gravitacionais. Para o programa neoclássico de pesquisa é a Teoria de Equilíbrio Geral de origem walrasiana. Essas hipóteses do núcleo rígido não podem ser rejeitadas nem modificadas. O núcleo tem um caráter ideal e é protegido por um cinturão protetor de hipóteses auxiliares e de teorias que visam dar conta de fenômenos mais próximos do real, essas últimas teorias passíveis de serem testadas (LAKATOS,1974). 
Em termos conceituais, a defasagem teórica que se constata na periferia em relação à reflexão sobre o capitalismo das economias centrais se traduziu em vantagens. Primeiro, na possibilidade de se aproveitar das teorias existentes, adaptando-as; e segundo, na criação de novos conceitos que tratam das especificidades do desenvolvimento do capitalismo brasileiro, ainda que integrado ao movimento mais geral do capital.

Podemos observar uma adaptação equivocada de conceitos na identificação de relações feudais nas análises sociais do campo brasileiro, uma tese determinista oriunda do Partido Comunista Brasileiro (PCB). Outro exemplo de adaptação teórica sem mediações são os arranjos das teorias do crescimento e da teoria do capital humano da teoria mainstream aplicadas à análise do capitalismo brasileiro. De outro modo, presenciamos adaptações com mediações, que resultam em importantes contribuições na HPEB, como as aplicações da teoria do ciclo kaleckiana feitas por Maria da Conceição Tavares e João Manuel Cardoso de Mello na análise dos elementos endógenos da dinâmica do modelo de acumulação capitalista no Brasil. Já o aparecimento de ideias absolutamente originais é uma das faces interessantes do processo de conhecimento, em que conceitos como o de dualidade estrutural e de subdesenvolvimento de Celso Furtado iluminam não apenas a nossa história, mas também fornecem novas contribuições à compreensão do movimento mais geral do capital.

Um exemplo marcante de especificidade teórica é a temática central do desenvolvimento/subdesenvolvimento como estruturador da história do pensamento econômico-social no Brasil. Parece óbvio, mas foram as injunções históricas do capitalismo que fizeram da HPEB uma história organizada em torno do conceito de desenvolvimento. E será o conceito elaborado por Celso Furtado que marcará o nascimento da HPEB intimamente imbricado à economia política do desenvolvimento, como constatou primeiramente Ricardo Bielschowsky, na análise dos ciclos ideológicos de desenvolvimento e, como constata Guido Mantega, que responsabiliza Furtado pelo surgimento de uma economia política engajada na descoberta do desenvolvimento econômico. Será também o conceito de desenvolvimento que organiza a HPEB, lida como espaço das controvérsias em Malta et al. (2009).

Para Furtado $(1959,1961)$, o conceito de desenvolvimento, como bem assinala Ricardo Bielschowsky, traduz a íntima articulação que deve existir entre os elementos: Estado e as estruturas produtiva e distributiva, ou o Estado como promotor de mudanças estruturais na produção acompanhadas de melhorias na distribuição de renda. ${ }^{5}$

5 Em O Mito do Desenvolvimento Econômico, publicado em 1974, Celso Furtado amplia o seu conceito de desenvolvimento, desmistificando a ideia de progresso e de desenvolvimento dos países centrais, posto que não são levadas em conta nem as questões ambientais nem as culturais (FURTADO, 1974). 
A ideia de Furtado $(1959,1961)$ sobre o papel do Estado na construção das nações periféricas é o de fomentar a industrialização para superar a pobreza e o subdesenvolvimento. Entretanto, tanto a força da ideia do nacional quanto da participação ativa do Estado apresentam-se aqui com naturezas distintas das economias centrais. A formação dos Estados Nacionais nas economias centrais, encarnada na figura do príncipe do Estado-Nação, traduziu-se na unidade e na conformação das sociedades europeias e na viabilização do processo de acumulação primitiva de capital.

Já o "nacional", nas nossas circunstâncias históricas, vem articulado - em sua forma mais madura - a uma ideologia nacional-desenvolvimentista, alavanca de um processo de industrialização no quadro de um capitalismo constituído. Isso vai exigir, por força da história, um Estado que intervenha deliberadamente no plano econômico e social e que assuma a responsabilidade na condução de políticas voltadas para superação do atraso e da pobreza.

A gestação da ideologia nacional/desenvolvimentista marca um período que, segundo Bielschowsky (1988), é doutrinário por excelência (período 1945/1955). ${ }^{6}$ Podemos supor, dentro da visão khuniana, que estaríamos num momento pré-científico ${ }^{7}$ da formação e de desenvolvimento da ciência, em que as controvérsias, embora num campo doutrinário, refletem perspectivas que disputam a melhor compreensão do capitalismo brasileiro: uma vocação agrária se contrapondo às primeiras formulações industrial-desenvolvimentistas. ${ }^{8}$ A ruptura transformadora da modernização industrializante foi o quadro econômico da elaboração de uma teoria do desenvolvimento e de uma análise do nosso subdesenvolvimento elaborada por Furtado, responsável pelo pensamento inaugural sistematizado da HPEB.

Se, para Furtado $(1959,1961)$, desenvolvimento deve vir acompanhado de melhorias de distribuição de renda, para os adeptos da ordem do mercado o desenvolvimento terá sempre uma fase sem distribuição de renda, e até com concentração de renda, como aconteceu com a implantação do modelo autoritário de desenvolvimento.

O Estado como necessário no processo de desenvolvimento parece estar presente em todas as correntes teóricas. Entretanto, existe uma diferença substancial entre a perspectiva ortodoxa neoclássica e a perspectiva crítica. A aceitação pela primeira do papel do Estado é funcional (no sentido de útil) e circunscrita a determinados momentos da história do capitalismo (no sentido de descartável), enquanto, para as correntes da economia crítica, ela é a condição de viabilização do processo de acumulação e distribuição de renda

6 Já para Fonseca (2004), o desenvolvimentismo como ideário do processo de desenvolvimento pode ser observado nas suas primeiras formulações na prática política do Primeiro Governo Vargas.

7 Thomas Khun define etapas do progresso científico. Primeiro ocorre um pré-científico, em que as teorias (algumas ainda com forte conteúdo doutrinário) disputam a hegemonia, um período de ciência normal em que se tem um paradigma dominante e períodos de rupturas e de mudanças de paradigmas expressos nas revoluções científicas (KHUN, 1982).

8 Ou, como nos diz Bresser-Pereira (1997, p. 19), integrando a economia à literatura e à arte: “[...] era a ideia de um Brasil macunaímico da Semana de Arte Moderna, [...] o Brasil da Casa Grande e Senzala de Gilberto Freire, [...] o Brasil ufanista de Afonso Celso e o Brasil agrícola de Gudin". 
num país capitalista tardio. Para a ortodoxia e, sobretudo, para a sua face neoliberal das últimas décadas do século XX, assim que a estrutura produtiva se moderniza e o capitalismo amadurece, o Estado deve recuar ao seu mínimo. ${ }^{9}$

\section{A HPEB é marcada pela pluralidade}

Como destacamos, a busca pela compreensão das economias retardatárias surge no quadro de teorias maduras sobre o capitalismo constituído nas economias centrais. A história do pensamento econômico brasileiro é fundada no século XX, tendo em vista uma pluralidade de reflexões acumuladas na história do pensamento e que se apresentam aos nossos pensadores como a base de referência para as primeiras formulações teóricas sobre o capitalismo brasileiro.

Nesse sentido, a HPEB nasce marcada pela pluralidade de suas concepções, isto é, para um mesmo fenômeno são possíveis várias leituras. Entretanto, a constatação da pluralidade nesse caso não significa que as teorias partam de uma igualdade de posições ("igualdade de oportunidades") e que a retórica do convencimento definiria o melhor argumento, a melhor teoria. A história nos mostra que as articulações políticas podem fazer sobreviver em determinados momentos certas teorias e alijar outras, dependendo dos interesses políticos de grupos que estão em jogo dentro da sociedade. A história dos fatos e das ideias do Brasil não foge a essa regra. Veremos isso mais adiante.

A pluralidade no Brasil está expressa tanto na variedade de teorias como nos autores, que, regra geral, sofrem uma gama de influências teóricas. Celso Furtado, por exemplo, o autor central do nascimento do pensamento econômico brasileiro constrói, a partir de múltiplas matrizes, uma teoria capaz de explicar a realidade brasileira e latino-americana em contraposição às teses do Partido Comunista Brasileiro (PCB) e do Instituto Superior de Estudos Brasileiros (ISEB). Seu pensamento está associado às várias matrizes teóricas do centro (Marx/ Keynes/Weber) e ao estruturalismo da Cepal. Num primeiro momento, sua obra é difusora da teoria estruturalista do subdesenvolvimento, elaborada pela Cepal, que mostra que as economias periféricas em contraste com as centrais têm baixa diversidade produtiva e elevada heterogeneidade tecnológica, e se especializam em bens primários, elementos pouco favoráveis a um processo de acumulação produtiva. Para Furtado (1966), a única saída era a industrialização como forma de superar a pobreza. Em sua trajetória teórica, Furtado articula a dimensão histórica ao método estrutural de origem cepalina e uma importante

9 O exemplo histórico dessa mudança pode ser observado na trajetória teórica/ideológica de Roberto Campos, em que o economista evolui de planista nas décadas de 1950/1960 para um dos maiores defensores do mercado autorregulável a partir dos anos 1980. Roberto Campos, autor teórico e operador político importante do período, defendeu em dois momentos a necessidade de intervenção do Estado para acelerar o processo de crescimento, no período JK e no golpe de 1964. Entretanto, em que pese a posição de Campos (aparentemente não ortodoxa) sobre a importância do Estado para o crescimento econômico nesses dois momentos, sua perspectiva de desenvolvimento situa-se nas antípodas daquela de Celso Furtado. Além disso, assim que o capitalismo se consolida no Brasil, Roberto Campos será um dos maiores defensores do Estado mínimo e da capacidade do mercado se autorregular (GANEM, 2000). 
contribuição teórica surge na HPEB: a ideia do subdesenvolvimento como um sistema que tenderia à concentração de renda e a um grau de injustiça social crescente. Além disso, Furtado teceu comparações com as economias latinoamericanas, em Formação Econômica da América Latina, evidenciando suas identificações e particularidades. Seu método histórico-estrutural lhe permitiu dar os primeiros passos rumo ao entendimento da dinâmica da economia capitalista brasileira, seus impulsos e suas contradições.

Caio Prado Junior, outro autor importante do pensamento econômicosocial brasileiro, critica duramente as teses etapistas do PCB e sistematiza uma nova interpretação sobre o Brasil. $\mathrm{O}$ autor, dentro da matriz marxista, descreve as relações de exploração capitalistas e mostra que uma industrialização com forte intervenção estatal pode funcionar como uma fase para a implantação do socialismo. Em que pese a importância e a influência de Caio Prado Júnior no pensamento econômico-social brasileiro, Celso Furtado é considerado, pela maior parte dos autores da HPEB, o pai da economia política no Brasil.

O golpe de 1964 e a mudança nos rumos políticos da nação através de um regime autoritário deixam claras as diversas e conflitantes perspectivas de autores e de escolas na HPEB. A ditadura viabiliza na prática o pensamento econômico conservador e provoca questões que aceleram a produção do pensamento crítico no intuito de compreender os rumos da acumulação capitalista no Brasil e apresentar soluções alternativas.

Instaura-se, pela ortodoxia de direita no poder, um novo padrão de acumulação, um novo modelo de desenvolvimento, o sustentáculo do Plano de Ação Econômica do Governo (PAEG). O modelo propunha que o Estado exercesse o planejamento aliado a uma política de compressão do nível de demanda (política de arrocho salarial) e uma abertura ao capital estrangeiro. Segundo Mantega, foram várias as influências teóricas que a ortodoxia sofreu. A concepção pragmática adotada pelos ideólogos do desenvolvimentismo autoritário vinha, por exemplo, de vários autores. Nurske, por exemplo, afirmara que os países subdesenvolvidos estavam mergulhados num círculo vicioso de estagnação; Hans Singer concluiu que a poupança dos países subdesenvolvidos vinha da desigualdade na repartição de renda, e que estes, portanto, deveriam ter sua propensão a poupar aumentada para alavancar os investimentos necessários. Essa seria, em essência para Mantega, "[...] a perspectiva pragmática da concentração de renda incondicionalmente adotada pelos ideólogos do desenvolvimentismo autoritário brasileiro" (MANTEGA, 1997, p. 114).

Intrinsecamente articulada a esse programa pragmático estava "a ideologia do desenvolvimento econômico com segurança nacional”, uma doutrina anticomunista radical e ideia-chave do agente ideológico principal do golpe, a Escola Superior de Guerra (ESG) .O golpe traduz-se dentro do Estado brasileiro em uma mudança de enfoque do ideário desenvolvimentista: dos estudos críticos sobre o desenvolvimento a uma teoria ortodoxa imposta e legitimada pela ditadura. E será ele também, o golpe de 1964, que dividirá, segundo nossa opinião, a HPEB em dois momentos políticos importantes, delineando claramente correntes teóricas sob matrizes diferenciadas e multiplicando o campo das controvérsias. 
Com a instauração da ditadura militar algo inesperado se constata: o capitalismo cresce com arrocho salarial. Para Furtado (1966), entender o capitalismo no Brasil (ou a sua formação histórica) era identificar um processo de industrialização com subemprego e concentração de renda: uma tendência à estagnação derivada da elevação na relação capital-produto. A única saída vista por Furtado àquele momento era um processo de desconcentração de renda que aumentasse empregos e salários, ampliando o mercado interno, sua fórmula básica para o desenvolvimento: um crescimento integrado à redução das desigualdades sociais sob a égide do Estado.

Entretanto, novas leituras surgem dentro do campo crítico e uma importante controvérsia, destacada por Malta et al. (2009), se instaura entre Furtado e alguns de seus discípulos. Em Além da Estagnação, Tavares e Serra (1973) se contrapõem à tese estagnacionista de Furtado explicando a emergência de um novo padrão de desenvolvimento do capitalismo, em que era possível crescer concentrando renda. E mais, que essa mesma concentração alimentava o processo de crescimento acelerado de forma desigual, incorporando e excluindo. $\mathrm{O}$ argumento de fundo era que o capitalismo brasileiro se desenvolvia dependente e associado ao grande capital internacional.

A partir daí, tornaram-se cada vez mais necessárias teorias que explicassem a dinâmica do capitalismo nas economias tardias e que fizessem uma releitura do Estado e das forças políticas e sociais dando conta dessa nova conjunção. A análise dos pensadores dentro da matriz de Furtado avançou no sentido de compreender o modelo endógeno de acumulação, em que a economia capitalista exportadora presidida pela lógica de acumulação do capital mercantil dava lugar a uma fusão do capital mercantil e agrário, comandada pela lógica da acumulação industrial. ${ }^{10}$ Eles aprofundaram as questões sobre que tipo de desenvolvimento capitalista estava em curso, descrevendo os elementos de um modelo endógeno de acumulação através de uma adaptação teórica dos ciclos de Kalecki. As duas teses inauguradoras dessa perspectiva e disseminadoras de vários outros trabalhos em série dentro desse campo crítico foram as teses de Maria da Conceição Tavares, Acumulação de capital e Industrialização no Brasil, publicada em 1974, e de João Manuel Cardoso de Mello, Capitalismo Tardio, publicada em 1975.

Também segundo Malta et al. (2009), outra importante controvérsia marca o período, deixando claras as diferentes concepções acerca do desenvolvimento, agora articuladas à questão da distribuição da renda. Um dado importante vem à tona, oriundo das informações do censo de 1970, mostrando estatisticamente o que já se sabia pela aplicação da política de arrocho salarial: a ocorrência de

Muitos trabalhos foram desenvolvidos no período articulados ou impulsionados por esses dois trabalhos pioneiros. Mantega sublinha entre outros: Sergio Silva, por ter esclarecido as relações entre o café e a indústria no Brasil, em 1973; Malan e Bonelli, em 1976, pela análise dos limites do crescimento localizados no déficit externo; Conceição e Belluzzo, em 1978, por apresentaram a tese da ciranda financeira em que a divida interna é reflexo da expansão de endividamento externo; Carlos Lessa, que, em 1975, publica importante contribuição em 15 anos de política econômica; Wilson Cano, com As raízes da concentração industrial, em 1977, e Liana Aureliano, No limiar da Industrialização, em 1981 (MANTEGA, 1997). 
um aumento de concentração de renda no Brasil nos anos 1960. Para Langoni (1973), a origem da desigualdade não estava na política econômica adotada ou na repressão política, mas na escolaridade. Para Simonsen, entretanto, a concentração era um sacrifício "natural e válido". Nesse momento, a economia política colocou no centro dos debates a possibilidade de compatibilizar crescimento com melhoria distributiva, desde que se alterasse a estratégia do desenvolvimento. Ricardo Tolipan e Artur Tinelli organizam um livro sobre a controvérsia da distribuição de renda no Brasil (1975), uma obra marcante do momento.

Voltando às leituras sobre o golpe e os caminhos econômico-sociais impostos por ele, temos os autores de tradição marxista que são André Gunder Frank, Ruy Mauro Marini e Theotônio dos Santos. Bielschowsky e Mussi (2005) os situam dentro da corrente socialista da Teoria da Dependência, Guido Mantega os denomina neomarxistas e Bresser-Pereira os inclui dentro da corrente da superexploração capitalista. Um eixo claro une esses autores: o fato de que as contradições do capitalismo conduziam inequivocamente à ideia de que só uma revolução socialista poderia viabilizar o desenvolvimento pleno do país.

Esses três autores da corrente socialista constroem, a partir da crítica à interpretação nacional-burguesa, uma nova interpretação para a América Latina, usando o conceito leninista de imperialismo e o conceito de desenvolvimento desigual e combinado de Trotski. Para Ruy Mauro Marini, baseado na tese da superexploração capitalista, o imperialismo extrai todo o excedente dos países subdesenvolvidos e ainda replica a exploração. Isso significa que o subdesenvolvimento é uma recriação do imperialismo, uma vez que as metrópoles subtraem todo o potencial de acumulação, repetindo o esquema metrópole-satélite.

Ainda dentro da matriz marxista cumpre destacar as importantes contribuições de Francisco de Oliveira e Florestan Fernandes. Francisco de Oliveira, em Crítica à Razão Dualista, pensa a economia brasileira não como um país subdesenvolvido, mas como um modo de produção no qual a indústria passa a ser o setor-chave para a dinâmica do sistema. Partindo de conceitos marxistas como modo de produção, dominação, exploração e maisvalia, ele conclui que não há contradições entre os elementos pré-capitalistas da formação social brasileira e a lógica de acumulação capitalista. Segundo Mantega, Francisco de Oliveira aponta tanto as limitações da teoria cepalina, em que o arsenal teórico é dúbio (marxista e liberal), como os equívocos e limitações das análises neoclássicas e keynesianas (MANTEGA, 1997).

Já Florestan Fernandes, considerado um dos nossos maiores pensadores sociais, caracteriza-se por um pensamento independente e complexo, o que impede classificações simplistas. Em seu estudo sobre a especificidade da revolução burguesa, ele não adere nem à perspectiva da economia política que estava em curso, nem à teoria da superexploração. 
A participação de Florestan Fernandes e de Caio Prado Júnior em controvérsias fundamentais no período atesta não apenas a pluralidade, mas também a presença da interdisciplinaridade na história do pensamento econômico brasileiro, assunto que trataremos a seguir.

\section{A HPEB é interdisciplinar}

A Economia Política Brasileira é interdisciplinar: como história é simbiótica à história do capitalismo; como sociologia exige que se articule a economia às classes sociais; e como ciência política espera-se que sejam decifradas as peculiaridades dos grupos de poder e do papel do Estado como promotor no processo de desenvolvimento.

A interdisciplinaridade é uma questão epistemológica interessante para o entendimento da HPEB, pois ela se afirma no Brasil como parte integrante da reflexão e não como uma fragilidade a ser superada como entendem os economistas positivos do centro.

$\mathrm{Na}$ constituição do pensamento econômico, a exigência imposta pelos padrões da física apontou para o caminho em que o estatuto de uma ciência (autônoma) passava expressamente pela expulsão do príncipe e da moral. No século XIX, os adeptos da autonomia e da neutralidade da economia positiva construíram um modelo abstrato, ideal, de um mercado autorregulável: a Teoria do Equilíbrio Geral de origem walrasiana. O desejo dos neoclássicos de se espelhar na física e a eleição da matemática como único critério de cientificidade gerou um empobrecimento da economia expresso no reducionismo e na ideia de que só é científico aquilo que for capaz de ser traduzido num modelo matemático. Por outro lado, foi no próprio século XIX que, sob o silêncio imposto à abordagem crítica, os adeptos da noção de que não existe ciência neutra construíram a interpretação dialética e interdisciplinar da economia política, expresso na perspectiva marxista da história.

Não é por outra razão que refletir sobre a história do pensamento econômico no centro nos conduz inequivocamente a análises epistemológicas acerca das diversas concepções de ciência. Isso significa inquirir acerca de qual concepção de economia está em jogo, se da economia entendida como análoga à física, uma ciência positiva, livre de valores ou se, ao contrário, ela é entendida como uma ciência social complexa, historicamente constituída, interdisciplinarmente praticada e pensada.

Duas questões surgem no campo da epistemologia crítica. A primeira é a avaliação dentro da HPE das consequências do processo de autonomização, axiomatização e matematização da ciência econômica. $O$ que se constata é que esse caminho axiomático da economia vem tornando a ciência econômica cada vez mais restrititiva, complicada e irrelevante. A segunda questão é o enfrentamento do desafio epistemológico para as ciências sociais, e para a economia em particular, da necessidade de criação de uma metodologia de 
convergência. Pensando hipoteticamente, essa metodologia refutaria todo e qualquer reducionismo, daria abrigo a uma interdisciplinaridade perdida com as ciências irmãs, transporia as fronteiras e ainda tomaria de empréstimo umas as outras disciplinas, seus esquemas conceituais de análise. Como consequência, teríamos uma nova história a ser contada que daria conta de forma rica da especificidade dos objetos das ciências sociais.

No Brasil, o esforço de compreender o nosso capitalismo se fez desde o seu nascedouro, entrelaçando o pensamento econômico de Marx e Keynes à sociologia de Weber e ao estruturalismo cepalino. Além disso, presenciamos historiadores, economistas, sociólogos, cientistas políticos e geógrafos, em reflexões que interagem e se somam acerca do capitalismo no Brasil. As reflexões sobre classes, Estado e estrutura de poder de Gilberto Freyre, Caio Prado Júnior, Sérgio Buarque de Holanda, Nelson Werneck Sodré, Luis Costa Pinto, Fernando Henrique Cardoso, Enzo Falleto, Francisco de Oliveira, Ruy Mauro Marini, Teothônio dos Santos, Florestan Fernandes, Octavio Ianni e José Luis Fiori, para citar alguns exemplos, vêm mostrar que elas são constituintes do pensamento econômico e não seus apêndices.

Entretanto, em que pese os esforços dos sistematizadores em apontar para esse caminho interdisciplinar na leitura da HPEB (citando cientistas sociais de outras áreas), o entrelaçamento das contribuições teóricas da economia com as demais áreas das ciências sociais ainda está por ser feito.

Um bom exemplo de interdisciplinaridade na HPEB se observa nas décadas de 1960 e de 1970, em que a temática da teoria da dependência se desloca para o centro dos debates, impulsionando estudos sobre classes sociais, o caráter do Estado e a importância das alianças políticas. A teoria da dependência cepalina concentrava-se nas relações comerciais e não fazia uma análise da estrutura de dominação. Fazia-se, portanto, necessário superar o enfoque estrutural e entender o processo histórico em seus aspectos econômicos, articulando-o à atuação das classes e dos grupos políticos. E foi assim que ocorreu dentro da tradição marxista em Caio Prado Júnior, Gunder Frank, Ruy Mauro Marini, Theotônio dos Santos e Francisco de Oliveira, e na teoria da dependência de Fernando Henrique Cardoso e Enzo Faletto. Nesta última é realizada uma análise do comportamento das classes sociais e das estruturas de poder econômico e político, tanto no seu movimento interno como nas relações com o poder das economias centrais.

As teorias da dependência, em seu conjunto e sob matrizes diferenciadas, além de expressarem um enorme avanço em direção a uma teoria do desenvolvimento de países capitalistas retardatários, articularam a economia à sociologia e à ciência política. Os economistas políticos, por sua vez, avançaram na ideia de uma análise integrada entre economia, história, classes sociais e poder. Este último ponto nos remete a mais uma das especificidades da HPEB: o grau de articulação da teoria com a ação política do país, assunto que trataremos a seguir. 


\section{A HPEB, a Política e as Instituições de Pós-Graduação nas Décadas de 1960 e 1970}

Os primeiros centros de pós-graduação em economia criados na segunda metade da década de 1960 no Brasil foram a Escola de Pós-Graduação em Economia da Fundação Getúlio Vargas (EPGE/FGV), o Programa de PósGraduação em Economia da Universidade Federal de Pernambuco (PIMES,/ UFPE), o Centro de Desenvolvimento e Planejamento Regional da Universidade Federal de Minas Gerais (CEDEPLAR/UFMG), o Instituto de Pesquisas Econômicas da Universidade de São Paulo (IPE/USP), o Instituto de Estudos e Pesquisas Econômicas da Universidade Federal do Rio Grande do Sul (IEPE/ UFRGS), a Pós-Graduação em Economia da Universidade Federal do Ceará (CAEN/UFCE) e a Universidade de Brasília (UnB). Esses centros, conforme observa Versiani (1997), possuíam uma característica dominante: a de serem cursos de aperfeiçoamento, cujo objetivo maior era o de suprir as deficiências dos cursos de bacharelado em economia e preparar quadros para o governo.

$\mathrm{Na}$ esteira da ebulição intelectual e do debate político-econômico da década de 1970, constata-se a criação de centros críticos, como foram os casos da Universidade Estadual de Campinas (Unicamp), em 1977, e do Instituto de Economia Industrial da Universidade Federal do Rio de Janeiro (IEI/UFRJ), em 1979. O Instituto de Economia da UFRJ veio preencher no Rio de Janeiro uma lacuna importante no espaço crítico: "O Rio de Janeiro foi sempre um centro de concentração de oposicionistas ao regime militar e existia entre os estudantes uma grande demanda insatisfeita por um curso de pós-graduação com perfil heterodoxo" (LESSA; EARP, 2004, p. 8). Além desses, foram criados, nessa década, a Universidade Federal da Bahia (UFBA), o Núcleo de Altos Estudos Amazônicos da Universidade Federal do Pará (NAEA/UFPA) e a Pós-Graduação em Economia da Pontifícia Universidade Católica do Rio de Janeiro (PUC/RJ). Em uma década e meia, tem-se o primeiro grande impulso na conformação da pós-graduação no Brasil, com um grande número de centros criados em quase todas as regiões do país, delineando perspectivas teóricas e perfis bem distintos (GANEM; TOLIPAN, 2000).

Uma dupla ingerência entre a produção do pensamento econômico nos centros e a política é também identificada. O golpe de 1964, por exemplo, divide a HPEB em duas partes, o que significa que ocorre uma ruptura política a partir dele, trazendo consequências para o campo teórico. Se pensarmos a extensão da influência política e ideológica do golpe para o campo da ciência, podemos supor que houve uma mudança importante de enfoque no seu interior: de estudos críticos voltados para a economia do desenvolvimento para uma teoria ortodoxa exposta e legitimada pelo golpe. Essa teoria caminhou no sentido contrário do difundido pela sabedoria estabelecida, de que o capitalismo sucumbiria se concentrasse mais renda. Entretanto, em que pese a legitimação devida ao sucesso dos planos implantados, estudos críticos avançaram no 
entendimento do padrão de acumulação capitalista. As teses produzidas pela Unicamp levam essa instituição ao primeiro plano do pensamento crítico brasileiro. Podemos considerar, pela quantidade e pela qualidade dos trabalhos germinados a partir das teses de Maria da Conceição Tavares e João Manuel Cardoso de Mello, que se estava diante dos anos de ouro da produção teórica de Campinas. O período 1968-1974 expressa a maturidade do ciclo desenvolvimentista, nos termos de Bielschowsky (1988), o que se traduz no sucesso e no auge da proposta política governista, mas é também o registro de um importante vigor na produção teórica crítica.

É inquestionável que a HPE se desenvolve e se realimenta da produção das instituições de pós-graduação. Em todos os países, a teoria é produzida pelos centros de pós-graduação, mas seus acadêmicos não necessariamente participam da política governamental. Aqui, talvez pela força dos desafios econômico-sociais apresentados na nossa história, observa-se um engajamento de parte da intelectualidade na política. "[...] o economista no Brasil, para o bem ou para o mal, nunca foi um cientista fechado nas chamadas 'torres de marfim' dos meios acadêmicos. Ao contrário, sempre correu o risco de sujar as mãos. Neste sentido, a Economia brasileira sempre foi uma economia política" (LOUREIRO, 1997, p. 12).

Os centros oferecem sistematicamente quadros para a política. A alternância na política de grupos oriundos da academia revela também as várias vertentes teóricas norteadoras dos centros de pós-graduação criados nesse período e nos subsequentes. A polaridade maior de orientações teóricas se verifica entre o mainstream e os centros considerados heterodoxos. Nesse sentido, o IE/UFRJ e a Unicamp estariam identificados com a perspectiva heterodoxa, enquanto a EPGE/FGV e a IPE/USP se ajustam mais ao modelo mainstream. Esses dois últimos centros foram criados por alguns dos executores da política dos anos de autoritarismo: Mario H. Simonsen criou a EPGE/FGV, e Delfim Netto participou da construção do Instituto de Pesquisas da USP.

\section{A HPEB e as Correntes do Pensamento Econômico Brasileiro}

Entendemos que, para melhor compreender a HPEB em sua característica plural e como espaço de controvérsias teóricas, faz-se necessário, ainda que forma geral, remeter as teorias e as controvérsias a correntes do pensamento ou a programas de pesquisa. Ao longo do trabalho pudemos identificar, de forma preliminar, três grandes correntes presentes na história do pensamento econômico brasileiro: uma economia política de corte estruturalista, uma economia política de tradição marxista e uma economia de origem neoclássica.

Para acompanhar as principais controvérsias e as principais teses defendidas pelas respectivas correntes no período em causa, agrupamos as contribuições que mais se destacaram dentro das seguintes três correntes teóricas: Economia Política Estruturalista, Economia Política Marxista e Economia Neoclássica. 
No campo da Economia Política Estruturalista identificamos:

1) ainda no período de gestação do pensamento econômico, o projeto de industrialização planejada (CEPAL/ISEB), que se opõe ao neoliberalismo (primeira controvérsia);

2) Celso Furtado constrói sua tese sobre o capitalismo subdesenvolvido no Brasil através do método histórico-estrutural (primeira tese);

3) ao construir uma teoria alternativa capaz de explicar a realidade brasileira e latino-americana, colocam-se em contraposição as teses do PCB e do ISEB (segunda controvérsia);

4) nem estagnacionismo nem as teses marxistas. Era possível o desenvolvimento do capitalismo no Brasil com exclusão. Em Além da Estagnação, Conceição e Serra (1969) se contrapõem à tese estagnacionista de Furtado, descrevendo um capitalismo onde era possível crescer concentrando renda (segunda tese /terceira controvérsia);

5) a Teoria da Dependência de FHC/Enzo Faletto (1970) traz uma análise do comportamento das classes sociais e das estruturas de poder econômico e político, tanto no seu movimento interno como nas relações com o poder das economias centrais (terceira tese);

6) os elementos sublinhados em FHC/Faletto teriam sido minimizados na interpretação nacional-burguesa e superestimados na teoria da superexploração (quarta controvérsia);

7) Paul Singer, em 1965, escreve Ciclos de Conjuntura em Economias Subdesenvolvidas, um dos primeiros trabalhos a descrever o movimento cíclico da economia brasileira através de seus condicionantes internos (quinta tese);

8) avançando na caracterização de um modelo endógeno de acumulação, surgem duas teses importantes disseminadoras de vários outros trabalhos em série: A tese do Capitalismo Tardio, de João Manuel Cardoso de Mello em 1975, e os trabalhos de Maria da Conceição Tavares: Acumulação de K e Industrialização no Brasil, em 1974, e Ciclo e Crise, em 1978 (sexta e sétima importantes teses). Inúmeros trabalhos surgem na esteira desses dois trabalhos centrais;

9) Castro rompe com a ideia de uma agricultura estagnacionista e com a perspectiva dualista de Furtado. Sua tese corrobora a ideia de que o sistema econômico se expande sem resolver as questões sociais, sem reformas sociais (oitava tese que corrobora as sexta e sétima teses);

10) Conceição e Belluzzo, em 1978, apresentam a tese da ciranda financeira, cuja divida interna é reflexo da expansão de endividamento externo (da nona tese);

11) a origem da desigualdade colocou no centro dos debates a possibilidade de compatibilizar crescimento com melhoria distributiva (quinta controvérsia); 
12) a Economia em Marcha Forçada, de Castro e Pires, faz uma crítica à ortodoxia a quem atribuíam a crise ao déficit público, ao excesso de intervenção do Estado na economia (décima tese e sexta controvérsia).

Já no campo da Economia Política Marxista, identificamos as principais teses defendidas e a participação dessa corrente nas seguintes controvérsias:

1) as teses etapistas do PCB foram criticadas pelas teses Caio Prado Junior (33/45) (primeira tese/ primeira controvérsia). A discordância com o PCB residia em que a agricultura não é feudal e as relações de produção são capitalistas;

2) Caio Prado Junior e a tese da industrialização como uma etapa para o socialismo em 1965 (segunda tese);

3) na ideia de que só a revolução socialista poderia libertar o país, temos Gunder Frank, Rui Mauro Marini e Theotônio dos Santos (segunda controvérsia);

4) Rui Mauro Marini formula a Tese da Superexploração Capitalista em 1969 (terceira tese). O imperialismo extrai todo o excedente dos paises subdesenvolvidos e replica a exploração. A superexploração significa o rompimento da troca de equivalentes e a força de trabalho deixa de ser paga de acordo com o seu valor;

5) Theotônio dos Santos, em 1970, identifica três formas de dependência: dependência colonial comercial exportadora, dependência financeiroindustrial e dependência tecnológico-industrial (multinacionais). Sua tese: socialismo ou fascismo (quarta tese);

6) Rangel construiu seu próprio quadro analítico e redefiniu a tese da dualidade básica da economia brasileira, assimilando, de forma crítica, as teses marxistas (quinta tese);

7) em 1972, Chico de Oliveira aponta as limitações da teoria cepalina em que o arsenal é dúbio, marxista e liberal, marginalistas e keynesianas (relação produto-capital) e parte dos conceitos marxistas de modo de produção, dominação, exploração e mais-valia para concluir que não há contradições entre os elementos pré-capitalistas da formação social brasileira e a lógica de acumulação capitalista (sexta tese);

8) Florestan estuda a especificidade da revolução burguesa, não aderindo nem à perspectiva da sociologia dependentista de FHC, nem à teoria da superexploração (sétima tese).

Finalmente no campo da Economia Neoclássica identificamos:

1) os primeiros defensores de uma economia ortodoxa neoclássica, nos anos 1940, foram Eugenio Gudin e Octavio Bulhões, que pregavam a redução da ação estatal, atração de capital estrangeiro, equilíbrio monetário e fiscal (primeira tese doutrinária/primeira controvérsia); 
2) a Teoria do Desenvolvimento Equilibrado, parte integrante do Modelo Brasileiro de Desenvolvimento, constitui-se na teoria-sustentáculo do PAEG. Ela propunha que o Estado exercesse o planejamento. Além disso, defendia compressão do nível de consumo (política de arrocho salarial) e uma abertura ao capital estrangeiro (segunda tese/segunda controvérsia);

3) o alto preço social pago pelos modelos de desenvolvimento autoritários foi uma das questões que mereceu acirrada crítica por parte da economia política. Simonsen, em 1972, justificou a concentração de renda alegando que ela é natural numa transição de estagnação para crescimento, que exige sacrifícios da transferência de recursos dos mais propensos a consumir aos mais propensos a poupar (terceira controvérsia);

4) Delfim Neto e o modelo de crescimento, que parte do modelo de Harrod/Domar e da introdução do progresso técnico. Desenvolvimento depende do excedente desde que transformado em capacidade aliada a novas formas de desenvolvimento tecnológico. Para viabilizar a poupança necessária aos investimentos, Delfim Neto usa o mesmo argumento de seus anteriores: uma política de arrocho salarial (terceira tese);

5) em fins dos anos 1980, assistimos a segunda geração de reformas proposta pela ortodoxia: flexibilização do mercado de trabalho, reforma da previdência, lei da falência. A chamada heterodoxia de Simonsen aparece na análise do combate à inflação, gradualismo x tratamento de choque (quarta tese). 


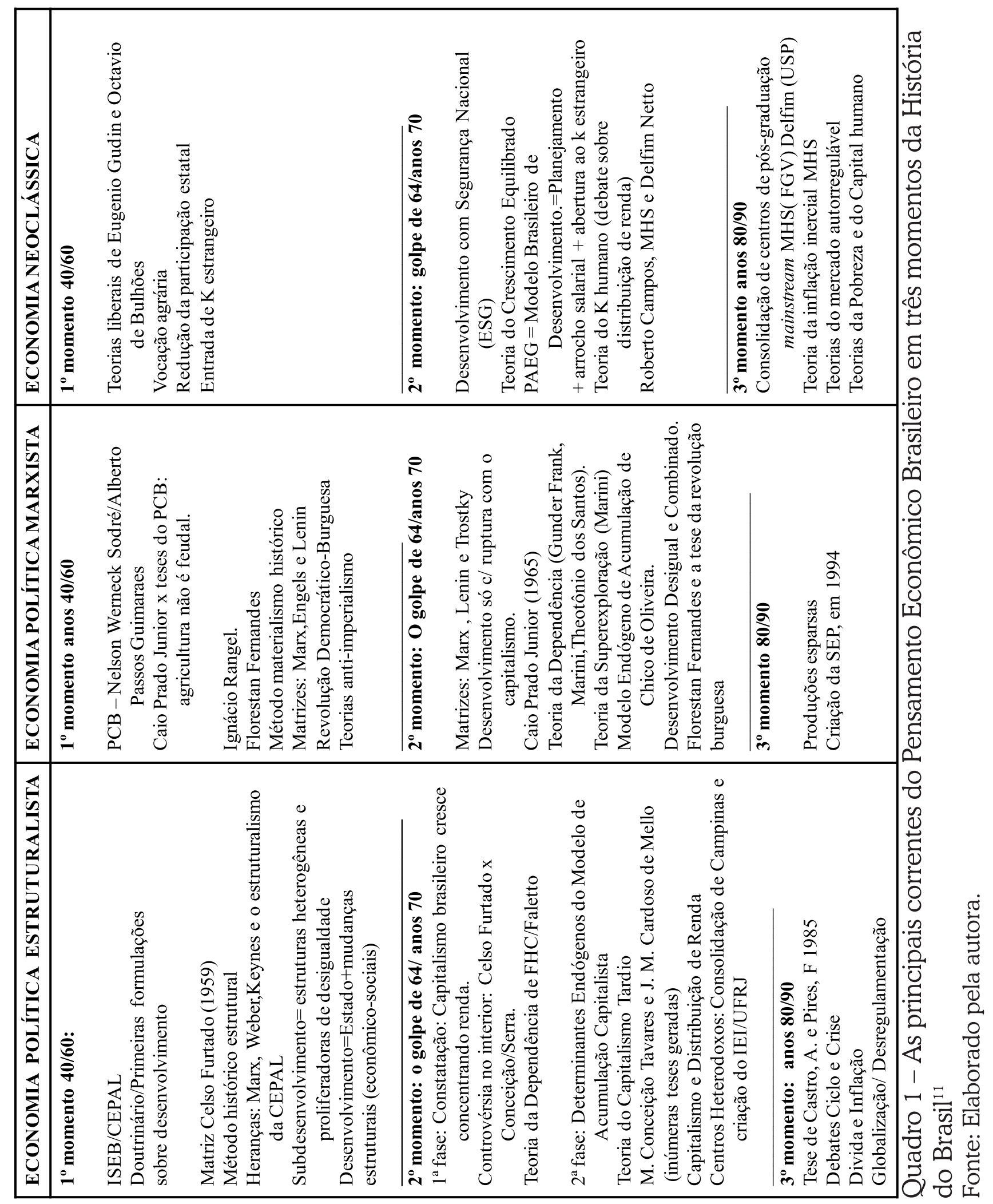

11 O terceiro momento, anos 1980-1990, ainda que não analisado no presente texto, identifica alguns traços marcantes dessas três correntes do pensamento econômico brasileiro. 


\section{Considerações Finais}

Vimos que é possível problematizar em torno da HPEB através de múltiplos aspectos. O primeiro deles trata das injunções impostas pela história do capitalismo e da influência das teorias na produção de nossos pensadores. As múltiplas influências teóricas estão expressas na pluralidade, tanto no plano autoral, como na presença de várias vertentes teóricas na HPEB. Essas influências sobre os pensadores se manifestam na riqueza das adaptações teóricas e conceituais, na criação de novos conceitos, ou ainda, de novas interpretações sobre questões importantes que definem o padrão de acumulação do capitalismo no Brasil.

E não é também por outra razão que o engajamento teórico na temática do desenvolvimento e da superação do subdesenvolvimento traduz-se na marca da nossa história econômica e política. Nesse sentido, o golpe de 1964 divide a HPEB em dois momentos importantes (antes e depois do golpe), pois a conjuntura de ditadura revelou e exacerbou as diferenças de perspectivas que se abrigavam sob o mesmo rótulo de desenvolvimentista. O golpe e o período da ditadura presenciaram correntes teóricas de matrizes diferenciadas defendendo suas posições e multiplicando o campo das controvérsias. A experiência de crescimento do capitalismo com exclusão não apenas alça e legitima a teoria ortodoxa, como provoca a produção dos economistas críticos no afã de compreendê-lo e de apontar soluções alternativas. O fim dos anos 1960 e a década de 1970 testemunharam uma grande riqueza teórica forjada pela necessidade de se compreender o capitalismo brasileiro.

Essa proliferação de ideias se manifestou no crescimento e na qualidade da produção teórica, nas inúmeras controvérsias que pautaram o período e, sobretudo, na aceleração da criação de centros de pós-graduação que se multiplicaram obedecendo a perfis teóricos distintos. A ligação dos economistas no Brasil com a prática política contribuiu para forjar a necessidade de uma formação institucionalizada que garantisse a ampliação de quadros de economistas tecnocráticos. Soma-se, então, às características de pluralidade e de interdisciplinaridade assinaladas na nossa HPEB a ideia de que o pensamento econômico no Brasil se faz e se consolida ligado à política e às instituições de forma imperativa.

\section{Referências}

BERTRAND, P. Histoire d'une question: das Adam Smith Problem. Journée d'Etudes de l'Association Charles Gide pour l'Étude de la Pensée Economique, Paris, 1994. Mimeo.

BIANCHI, A. M. A pré-história da economia: de Maquiavel a Adam Smith. São Paulo: Editora Hucitec, 1988.

BIELSCHOWSKY, R. Pensamento econômico brasileiro: o ciclo ideológico do desenvolvimento. Rio de Janeiro: IPEA; INPES, 1988. 
BIELSCHOWSKY, R.; MUSSI, C. O pensamento desenvolvimentista no Brasil: 1930-1964 e anotações sobre 1964-2005. Texto preparado para o Seminário "Brasil-Chile: uma mirada hacia América latina y sus perspectivas. Santiago de Chile, jul. 2005.

BRESSER-PEREIRA, L. C. Interpretações sobre o Brasil. In: LOUREIRO, M.R. (Org.). 50 anos de ciência econômica no Brasil: pensamento, instituições e depoimentos. Petrópolis: Vozes, 1997.

DUPUY, J. P. Le sacrifice et l'envie: le libéralisme aux prises de la Justice. Paris: Calmann-Levy, 1992.

FONSECA, P. C. D. Gênese e precursores do desenvolvimentismo no Brasil. Pesquisa e Debate, São Paulo, v. 15, n. 2, p 225-256, 2004.

FURTADO, C. Desenvolvimento e subdesenvolvimento, Rio de Janeiro: Fundo de Cultura, 1961. . Formação econômica do Brasil. Rio de Janeiro: Fundo de Cultura, 1959.

. O mito do desenvolvimento econômico. Rio de Janeiro: Paz e Terra, 1974.

. Subdesenvolvimento e estagnação na América Latina, Rio de Janeiro: Civilização Brasileira, 1966.

GANEM, A. Adam Smith e a explicação do mercado como ordem social: uma abordagem histórico-filosófica. Revista de Economia Contemporânea, Rio de Janeiro, v. 4, n.. 2, p. 9-35 2000.

. A defesa do mercado no Brasil: o pensamento apologético de Roberto Campos. Nova Economia, v. 10, n. 1, p.19-38, jul. 2000.

. A Teoria e o Método no Espelho da História. In: CORAZZA, G. (Org.). Métodos da Ciência Econômica. Porto Alegre: Editora da UFRGS, 2003.

. Demonstrar a ordem racional do mercado: considerações em torno de um projeto impossível. v. 16, n. 2, p.105-122 br.jun. 1996.

. Economia e Filosofia: tensão e solução na obra de Adam Smith. Revista de Economia Política, v. 22, n. 88, p.104-118, out./dez. 2002.

GANEM, A.; TOLIPAN, R.; A formação do economista no Brasil: o papel atual do ensino de Pósgraduação. Relatório de Pesquisa CNPq, 2000. Mimeo.

KHUN, T. S. A estrutura das revoluções científicas. São Paulo: Perspectiva, 1982.

LAKATOS, I. The methodology of scientific research programmes. Cambridge: Cambridge University Press, 1974.

LESSA, C.; EARP, F. S. Mais além do II PND: O Instituto de Economia da UFRJ. Rio de Janeiro: UFRJ, 2004. (Texto para Discussão, n. 011).

LOUREIRO, M. R. (Org.). 50 anos de Ciência Econômica no Brasil: pensamento, instituições e depoimentos. Petrópolis: Vozes, 1997. 
MALTA, M. M. et al. A história do pensamento econômico brasileiro entre 1964 e 1989: um método para discussão. In: ENCONTRO ANUAL DA ANPEC, 38., 2009, Foz do Iguaçu. Anais... Foz do Iguaçu: ANPEC, 2009.

MANTEGA,G., O Pensamento econômico brasileiro de 60 a 80: os anos rebeldes. In: LOUREIRO, M. R. (Org.). 50 anos de ciência econômica no Brasil: pensamento, instituições e depoimentos. Petrópolis: Vozes, 1997.

RAPHAEL, D. D.; MACFIE, A. L.; Introduction of the theory of moral sentiments. Oxford: Clarendon Press, 1976.

TAVARES, M. C. Acumulação de capital e industrialização no Brasil. Campinas: Unicamp, 1988.

TAVARES, M. C.; SERRA, J. Além da estagnação. In: TAVARES, M. C. Da substituição de importações ao capitalismo financeiro. Rio de Janeiro: Zahar Editores, 1973.

TOLIPAN, R. A necessidade do pensamento econômico. Rio de Janeiro: IE/UFRJ, 1982. (Texto para Discussão, n. 3).

TOLIPAN, R.; TINELLI, A. (Org.). A controvérsia sobre distribuição de renda e desenvolvimento. Rio de Janeiro: Zahar Editores, 1975.

VERSIANI, F. A ANPEC aos 25 anos: passado e futuro. Revista da ANPEC, n.1, p.219-259, agosto de 1997.

Recebido em: 03/11/2010. Aceito em: 10/04/2011. 